\title{
Combined treatment with cotylenin A and phenethyl isothiocyanate induces strong antitumor activity mainly through the induction of ferroptotic cell death in human pancreatic cancer cells
}

\author{
TAKASHI KASUKABE ${ }^{1}$, YOSHIO HONMA ${ }^{2}$, JUNKO OKABE-KADO ${ }^{3}$, YUSUKE HIGUCHI ${ }^{4}$, \\ NOBUO KATO $^{4}$ and SHUNICHI KUMAKURA ${ }^{1}$ \\ ${ }^{1}$ Department of Medical Education and Research, and ${ }^{2}$ Cancer Center, Faculty of Medicine, Shimane University, \\ Izumo 693-8501; ${ }^{3}$ Research Institute for Clinical Oncology, Saitama Cancer Center, Saitama 362-0806; \\ ${ }^{4}$ The Institute of Scientific and Industrial Research, Osaka University, Osaka 567-0047, Japan
}

Received January 22, 2016; Accepted March 2, 2016

DOI: 10.3892/or.2016.4867

\begin{abstract}
The treatment of pancreatic cancer, one of the most aggressive gastrointestinal tract malignancies, with current chemotherapeutic drugs has had limited success due to its chemoresistance and poor prognosis. Therefore, the development of new drugs or effective combination therapies is urgently needed. Cotylenin A (CN-A) (a plant growth regulator) is a potent inducer of differentiation in myeloid leukemia cells and exhibits potent antitumor activities in several cancer cell lines. In the present study, we demonstrated that $\mathrm{CN}$-A and phenethyl isothiocyanate (PEITC), an inducer of reactive oxygen species (ROS) and a dietary anticarcinogenic compound, synergistically inhibited the proliferation of MIAPaCa-2, PANC-1 and gemcitabine-resistant PANC-1 cells. A combined treatment with CN-A and PEITC also effectively inhibited the anchorage-independent growth of these cancer cells. The combined treatment with $\mathrm{CN}-\mathrm{A}$ and PEITC strongly induced cell death within 1 day at concentrations at which $\mathrm{CN}-\mathrm{A}$ or PEITC alone did not affect cell viability. A combined treatment with synthetic CN-A derivatives (ISIR-005 and ISIR-042) or fusicoccin J (CN-A-related natural product) and PEITC did not have synergistic effects on cell death. The combined treatment with CN-A and PEITC synergistically induced the generation of ROS. Antioxidants ( $N$-acetylcysteine and trolox), ferroptosis inhibitors (ferrostatin-1 and liproxstatin), and the lysosomal iron chelator deferoxamine canceled the synergistic cell death. Apoptosis inhibitors (Z-VAD-FMK and Q-VD-OPH) and the
\end{abstract}

Correspondence to: Professor Takashi Kasukabe, Department of Medical Education and Research, Faculty of Medicine, Shimane University, Izumo 693-8501, Japan

E-mail:kasukabe@med.shimane-u.ac.jp

Key words: cotylenin A, phenethyl isothiocyanate, proliferation, ferroptosis, pancreatic cancer cells necrosis inhibitor necrostatin-1s did not inhibit synergistic cell death. Autophagy inhibitors (3-metyladenine and chloroquine) partially prevented cell death. These results show that synergistic cell death induced by the combined treatment with $\mathrm{CN}-\mathrm{A}$ and PEITC is mainly due to the induction of ferroptosis. Therefore, the combination of $\mathrm{CN}-\mathrm{A}$ and PEITC has potential as a novel therapeutic strategy against pancreatic cancer.

\section{Introduction}

Pancreatic cancer is one of the most aggressive malignancies and is associated with high mortality and a 5-year survival rate of $\sim 5 \%$ (1). The lethality of pancreatic cancer is characterized by rapid invasion of the surrounding tissue, early metastatic disease, and poor responses to standard chemotherapy and radiotherapy (2). Surgical resection and chemotherapy regimens, which include gemcitabine, currently provide the best clinical benefits. Gemcitabine has been the reference drug for the treatment of this often fatal disease for more than 10 years (3). A number of new anticancer drugs have been introduced in the last decade with the aim of improving the survival of pancreatic cancer patients. Despite continuous efforts to develop new agents, none of the currently available chemotherapeutic agents have an objective response rate higher than $10 \%(4,5)$. Therefore, there is an urgent need to develop better therapeutic strategies for pancreatic cancer.

Several recent studies suggest that dietary phytochemicals offer chemopreventive effects against many types of malignancies (6). Furthermore, epidemiological evidence revealed an inverse relationship between the intake amount of dietary isothiocyanates (ITCs) and cancer risk (7,8). Among all ITCs, phenethyl isothiocyanate (PEITC) has reached the level of phase 2 clinical trials for lung and oral cancer prevention $(9,10)$. PEITC is a well-known phytochemical found in its glucosinolate precursor form in cruciferous vegetables such as watercress and broccoli $(9,11)$. Due to its potential use in preventive medicine and as a cancer therapeutic agent, PEITC has attained great significance as an anticancer agent (12). 
PEITC has been shown to inhibit cancer cell growth, survival, and angiogenesis in many cancer cell lines (9). Furthermore, it is a potent generator of reactive oxygen species (ROS) $(13,14)$. Drug screening studies recently discovered that Ras transformation renders cells sensitive to ROS-induced, non-apoptotic, iron-dependent mode of cell death $(15,16)$. This mode of programmed necrosis, termed ferroptosis, is characterized by the loss of redox homeostasis, increased lipid peroxidation, and inhibition by the small molecule ferrostatin-1 (Ferr-1) or iron chelator deferoxamine $(17,18)$. However, PEITC-induced ROS-ferroptosis pathway-mediated pancreatic cancer cell death has not yet been evaluated.

We previously determined whether inducers of differentiation in leukemia cells also have the ability to control the growth of solid tumors. Cotylenin A (CN-A), which is a fucicoccan-diterpene glycoside with a complex sugar moiety, was originally isolated as a plant growth regulator and has been shown to affect several physiological processes in higher plants (19). We previously reported that $\mathrm{CN}-\mathrm{A}$ exhibits potent differentiation-inducing activity in several human and murine myeloid leukemia cell lines and in leukemia cells freshly isolated from patients with acute myeloid leukemia (20-23). We recently demonstrated that $\mathrm{CN}-\mathrm{A}$ significantly potentiated the arsenic trioxide-induced inhibition of cell growth in a liquid culture, and arsenic trioxide-induced inhibition of anchorage-independent growth in a semisolid culture in human breast cancer cells (24). Furthermore, we found that the pretreatment with $N$-acetylcysteine, a typical ROS scavenger, significantly reduced combination treatment-induced cell growth inhibition (24). These findings suggest that oxidative responses are important events in the corporative inhibition of the growth of cancer cells induced by the combined treatment with $\mathrm{CN}-\mathrm{A}$ and arsenic trioxide. We then hypothesized that $\mathrm{CN}-\mathrm{A}$-induced antitumor activity against solid tumors including breast and pancreatic cancer is enhanced by ROS inducers. In the present study, we found that CN-A and PEITC, as a model ROS inducer to test this hypothesis, synergistically inhibited the proliferation of MIAPaCa-2, PANC-1 and gemcitabine-resistant PANC-1 cells. Our results also suggest that synergistic cell death induced by the combined treatment with $\mathrm{CN}-\mathrm{A}$ and PEITC is mainly due to the induction of ferroptosis, while CN-A or PEITC alone cannot induce ferroptosis in pancreatic cancer cells.

\section{Materials and methods}

Cell culture. The human pancreatic cancer cell lines MIAPaCa-2, PANC-1 and CFPAC-1 were purchased from the American Type Culture Collection (ATCC; Manassas, VA, USA). PANC-1/GR cells were obtained after a long-term culture in the presence of gemcitabine. These pancreatic cancer cells were cultured in RPMI-1640 medium supplemented with $10 \%$ fetal bovine serum (FBS) at $37^{\circ} \mathrm{C}$ in a humidified atmosphere of $5 \%$ carbon dioxide in air.

Materials. CN-A, ISIR-042, ISIR-005 and fusicoccin J (FC-J) were prepared as previously described $(19,25)$. PEITC, gemcitabine, 3-(4,5-dimethylthiazol-2yl)-2,5-diphenyltetrazolium bromide (MTT), $N$-acetyl-L-cysteine (NAC), trolox, Ferr-1, 3-methyladenine (3-MA), deferoxamine mesylate
(DFO), Mito-TEMPO, RPMI-1640 medium and DMEM/F12 medium were purchased from Sigma-Aldrich (St. Louis, MO, USA). 5-(and-6)-Chloromethyl-2',7'-dichlorodihydrofluorescein diacetate (CM- $\mathrm{H}_{2}$ DCFDA), an acetyl ester, was obtained from Invitrogen (Carlsbad, CA, USA). Z-VAD-FMK and liproxstatin were purchased from Selleckchem (Houston, TX, USA). Q-VD-OPH (QVD) was obtained from Tonbo Biosciences (San Diego, CA, USA). Chloroquine (CQ) and methyl cellulose were purchased from Wako (Osaka, Japan). Necrostatin-1s (Nec-1s) was obtained from BioVision (Milpitas, CA, USA).

Cell growth and viability. Cells were seeded at $1-3 \times 10^{4}$ cells $/ \mathrm{ml}$ into a 24-well multidish. After being cultured with or without test compounds for the indicated times, viable cells were examined by a modified MTT assay (26).

Assay of anchorage-independent growth. MIAPaCa-2 or PANC-1 cells $\left(2 \times 10^{3}\right.$ cells/well) were plated in RPMI-1640 medium supplemented with $10 \%$ FBS and $1.0 \%$ methylcellulose in a 24-well ultra-low attachment multidish (Corning, Corning, NY, USA). Colonies containing 10 or more cells were counted 12 days after seeding.

Measurement of ROS generation. The production of ROS was monitored by flow cytometry with CM- ${ }_{2}$ DCFDA (a derivative of DCF-DA) as a probe. Briefly, MIAPaCa-2 cells treated with CN-A and/or PEITC were incubated with $10 \mu \mathrm{M} \mathrm{CM}-\mathrm{H}_{2}$ DCFDA in phosphate-buffered saline (PBS) for $30 \mathrm{~min}$. After removing the probe, the cells were incubated in warm culture medium for $10 \mathrm{~min}$. The medium was removed, and the cells were detached with a brief treatment of $0.05 \%$ trypsin-EDTA solution. After the addition of fresh culture medium, the cells were collected by centrifugation, washed once with PBS and suspended in PBS. Fluorescence was monitored using a BD FACSCanto II flow cytometer (BD Biosciences, San Jose, CA, USA).

Statistical analysis. Values were compared using a two-tailed Student's t-test. Differences between the means were considered significant when P-values were $<0.05$.

\section{Results}

CN-A and PEITC synergistically inhibit the growth of human pancreatic cancer MIAPaCa-2 and PANC-1 cells. MIAPaCa-2, PANC-1 and CFPAC-1 cells were cultured with or without CN-A, PEITC or CN-A plus PEITC for 5 days. $\mathrm{CN}-\mathrm{A}$ and PEITC synergistically inhibited the proliferation of MIAPaCa-2 and PANC-1 cells (Fig. 1A and B). Although PEITC alone, even at a higher concentration $(8 \mu \mathrm{M})$, inhibited the growth of MIAPaCa- 2 cells to $\sim 50 \%$ of the control and $\mathrm{CN}-\mathrm{A}(10 \mu / \mathrm{ml})$ alone slightly inhibited the growth of MIAPaCa-2 cells, in the presence of CN-A $(10 \mu / \mathrm{ml})$, PEITC at 2, 4 or $6 \mu \mathrm{M}$ inhibited the growth of MIAPaCa-2 cells to $\sim 50, \sim 20$ or $\sim 10 \%$ of the control, respectively (Fig. 1A). Similar synergistic growth inhibition induced by $\mathrm{CN}-\mathrm{A}$ plus PEITC was observed in PANC-1 cells (Fig. 1B). CN-A and PEITC additively inhibited the proliferation of CFPAC-1 cells (Fig. 1C). In order to determine whether CN-A and PEITC 

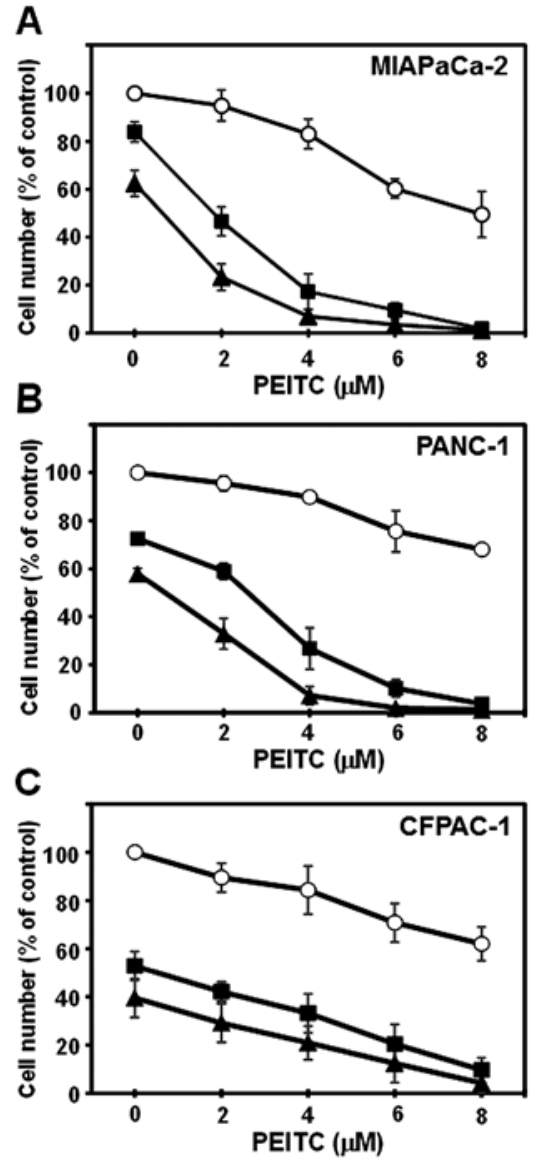

Figure 1. Effects of the combined treatment of cotylenin A (CN-A) and phenethyl isothiocyanate (PEITC) on cell proliferation in MIAPaCa-2, PANC-1 and CFPAC-1 cells. MIAPaCa- $2\left(1 \times 10^{4}\right.$ cells $\left./ \mathrm{ml}\right)$ (A), PANC-1 $\left(1 \times 10^{4}\right.$ cells $\left./ \mathrm{ml}\right)(B)$ and CFPAC-1 cells $\left(1 \times 10^{4}\right.$ cells $\left./ \mathrm{ml}\right)(\mathrm{C})$ were cultured with PEITC in the absence (open circle) or presence of $10 \mu \mathrm{g} / \mathrm{ml}$ (closed square) and $15 \mu \mathrm{g} / \mathrm{ml}$ (closed triangle) CN-A for 5 days. Cell numbers were then determined using the MTT assay. Values are expressed as the mean \pm standard deviation of 3 determinations.

A
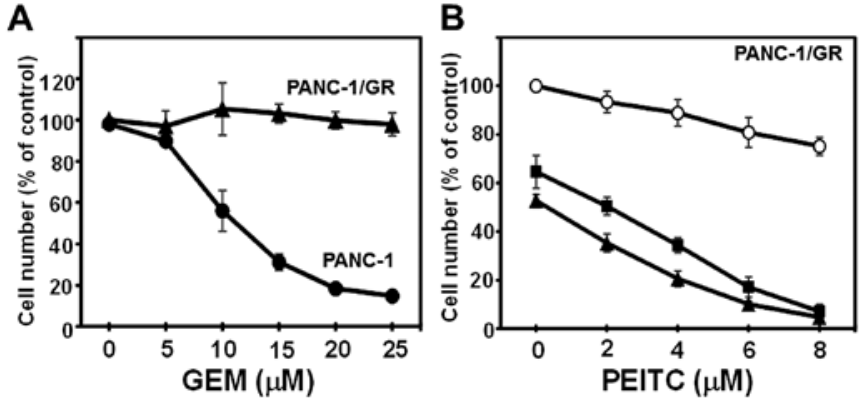

Figure 2. Effects of the combined treatment with CN-A and PEITC on cell proliferation in gemcitabine-resistant PANC-1 (PANC-1/GR) cells. (A) PANC-1 $\left(1 \times 10^{4}\right.$ cells $\left./ \mathrm{ml}\right)\left(\right.$ closed circle) and PANC-1/GR cells $\left(1 \times 10^{4}\right.$ cells $\left./ \mathrm{ml}\right)($ closed triangle) were cultured with gemcitabine (GEM) for 5 days. (B) PANC-1/GR $\left(1 \times 10^{4}\right.$ cells $\left./ \mathrm{ml}\right)$ cells were cultured with PEITC in the absence (open circle) or presence of $10 \mu \mathrm{g} / \mathrm{ml}$ (closed square) and $15 \mu \mathrm{g} / \mathrm{ml}$ (closed triangle) CN-A for 5 days. Cell numbers were then determined by the MTT assay. Values are expressed as the mean \pm standard deviation of 3 determinations.

inhibit the proliferation of chemotherapeutic drug-resistant pancreatic cancer cells, we obtained gemcitabine-resistant PANC-1 cells (PANC-1/GR) after a long-term culture in the
A
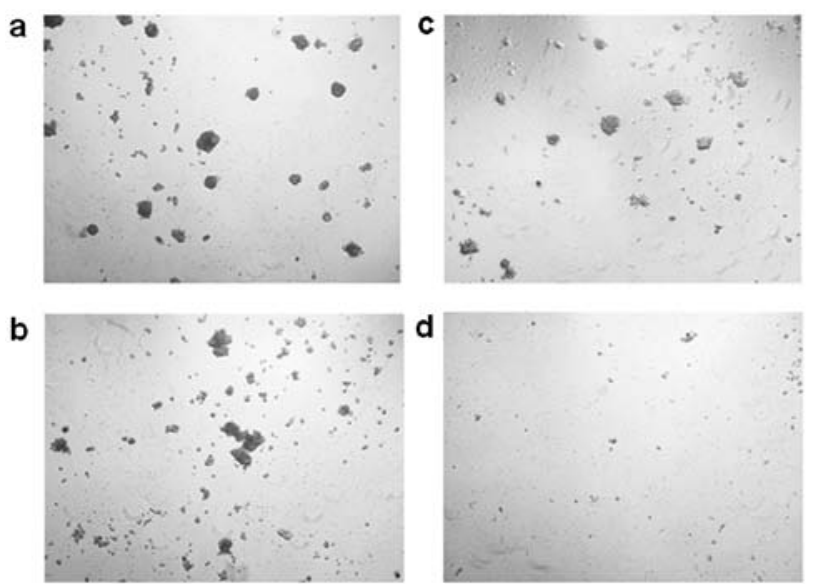

B

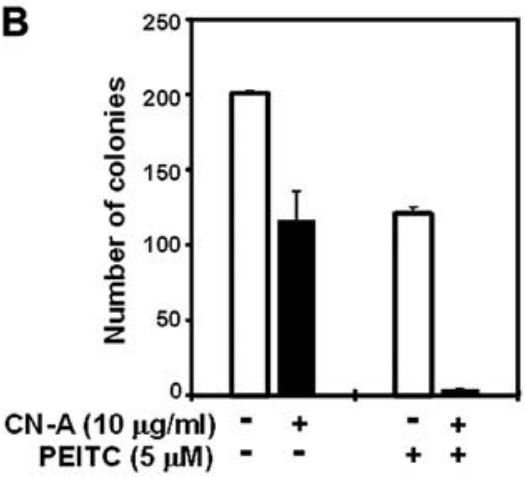

Figure 3. CN-A and PEITC synergistically inhibit the anchorage-independent growth of MIAPaCa- 2 cells. (A) MIAPaCa- 2 cells $\left(2 \times 10^{3}\right.$ cells/well) were cultured without (a) or with $10 \mu \mathrm{g} / \mathrm{ml} \mathrm{CN}-\mathrm{A}$ (b), $5 \mu \mathrm{M}$ PEITC (c) or $10 \mu \mathrm{g} / \mathrm{ml} \mathrm{CN-A} \mathrm{plus} 5 \mu \mathrm{M}$ PEITC (d) for 12 days in RPMI-1640 medium supplemented with $10 \%$ fetal bovine serum and $1.0 \%$ methylcellulose in a 24-well ultra-low attachment multidish. The results shown are representative of 3 independent experiments. (B) Colonies containing 10 or more cells were counted 12 days after seeding. Values are expressed as the mean \pm standard deviation of 3 determinations.

presence of gemcitabine (final concentration at $100 \mu \mathrm{M}$ ). Although the proliferation of the parental PANC-1 cells was dose-dependently inhibited by gemcitabine, the proliferation of PANC-1/GR cells was not inhibited by gemcitabine, even at $25 \mu \mathrm{M}$ (Fig. 2A). CN-A and PEITC also synergistically inhibited the proliferation of the PANC-1/GR cells (Fig. 2B).

$C N-A$ and PEITC synergistically inhibit the anchorage-independent growth of MIAPaCa-2 cells. Since anchorage-independent growth has been correlated with tumorigenic potential, we next investigated whether this combined treatment with $\mathrm{CN}-\mathrm{A}$ and PEITC effectively inhibits the anchorage-independent growth of these pancreatic cancer cells. Although CN-A $(10 \mu \mathrm{g} / \mathrm{ml})$ or PEITC (5 $\mu \mathrm{M})$ alone inhibited colony formation by MIAPaCa-2 cells to $\sim 60 \%$ of the control, the combined treatment with $\mathrm{CN}-\mathrm{A}$ and PEITC inhibited colony formation to $<5 \%$ of the control (Fig. 3A and B). CN-A and PEITC also synergistically inhibited the anchorage-independent growth of the PANC-1 cells (data not shown). cell death in the MIAPaCa-2 and PANC-1 cells after a short- 

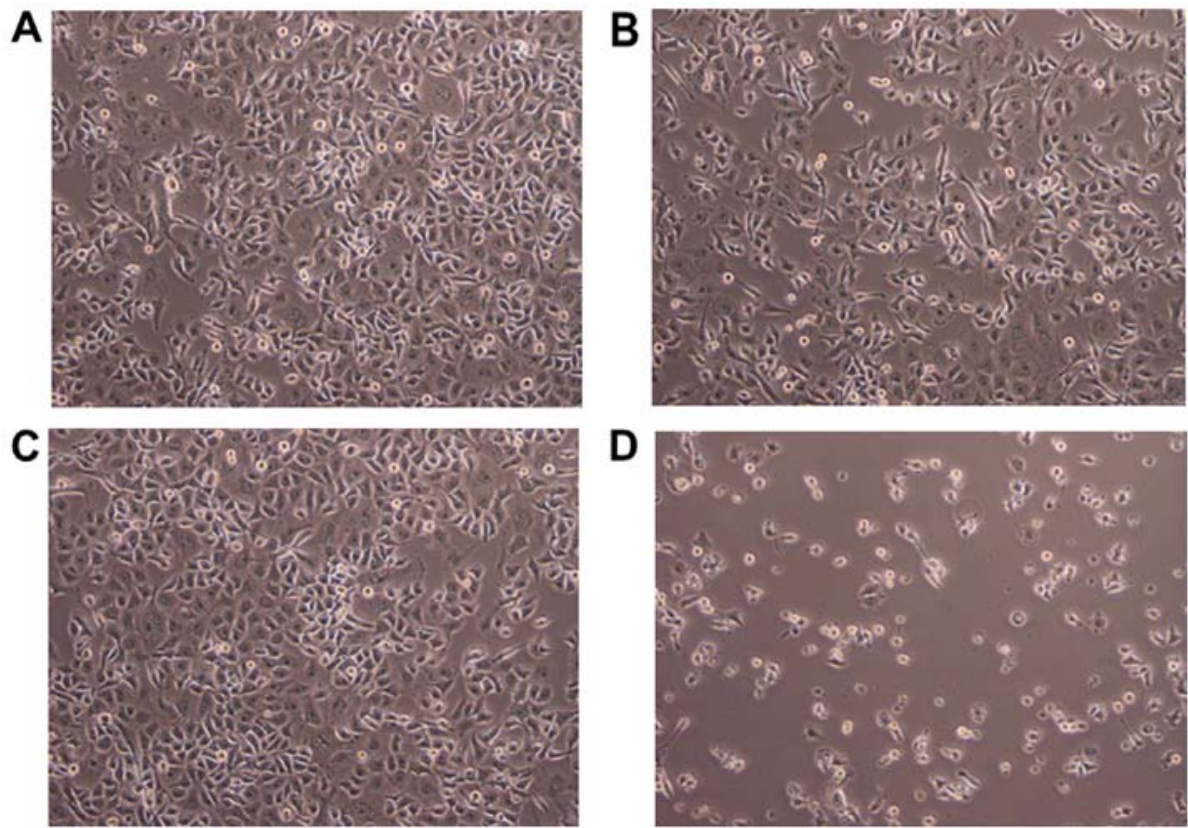

Figure 4. Induction of cell death in MIAPaCa-2 cells by the treatment with CN-A and PEITC. MIAPaCa-2 cells $\left(3 \times 10^{4}\right.$ cells/ml) were cultured without (A) or with $20 \mu \mathrm{g} / \mathrm{ml} \mathrm{CN}-\mathrm{A}$ (B), $5 \mu \mathrm{M}$ PEITC (C) or $20 \mu \mathrm{g} / \mathrm{ml} \mathrm{CN-A}$ plus $5 \mu \mathrm{M}$ PEITC for 1 day. Representative phase-contrast microscope images of 3 independent experiments are shown.
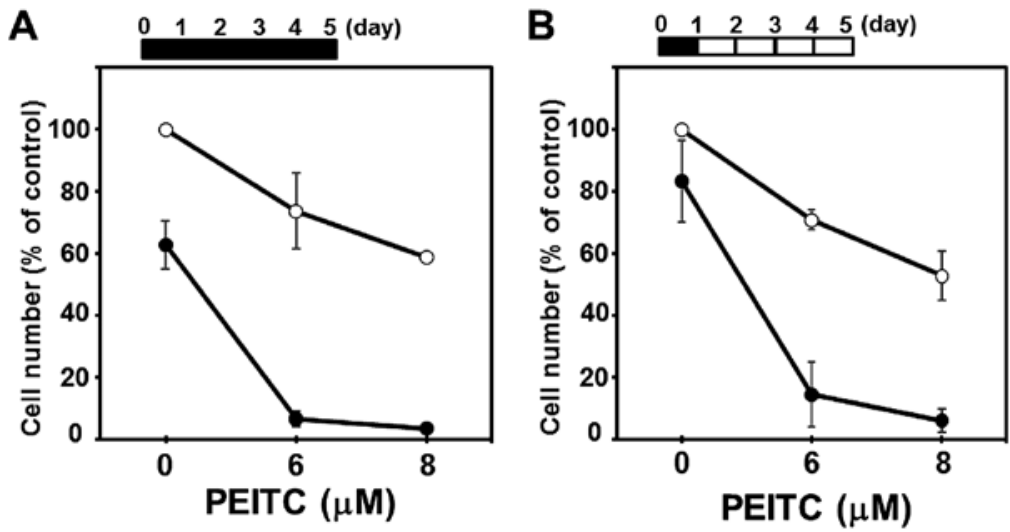

Figure 5. Effects of the treatment period with CN-A plus PEITC on the proliferation of PANC-1 cells. (A) PANC-1 (1x $10^{4}$ cells $\left./ \mathrm{ml}\right)$ cells were cultured with PEITC in the absence (open circle) or presence of $15 \mu \mathrm{g} / \mathrm{ml} \mathrm{CN-A}$ for 5 days. Cell numbers were then determined by the MTT assay. (B) PANC-1 (1x10 ${ }^{4}$ cells/ $\mathrm{ml}$ ) cells were cultured with PEITC in the absence (open circle) or presence (closed circle) of $15 \mu \mathrm{g} / \mathrm{ml} \mathrm{CN}$-A for 1 day. PANC-1 cells were washed with new RPMI-1640 medium and further cultured for another 4 days without CN-A or PEITC. Cell numbers were then determined by the MTT assay. Values are expressed as the mean \pm standard deviation of 3 determinations.

term culture. Although a 1-day treatment with CN-A $(5-20 \mu \mathrm{g} /$ $\mathrm{ml})$ or PEITC $(2-8 \mu \mathrm{M})$ alone did not markedly affect the viability of the MIAPaCa-2 and PANC-1 cells, the combined treatment with CN-A and PEITC for 1 day strongly induced cell death in the MIAPaCa-2 and PANC-1 cells (Figs. 4, 6A and 8; data not shown). We determined whether the effects of the combined treatment with $\mathrm{CN}-\mathrm{A}$ and PEITC for 1 day were sufficient to exert synergistic growth inhibition in a 5-day culture as described above (Fig. 1A and B). After PANC-1 cells were treated with CN-A $(15 \mu \mathrm{g} / \mathrm{ml})$ plus PEITC (6 or $8 \mu \mathrm{M})$ for 1 day, PANC-1 cells were washed and further cultured for another 4 days without CN-A or PEITC (Fig. 5B). At 5 days, the number of PANC-1 cells after the combined treatment with $\mathrm{CN}$-A plus PEITC for only 1 day was almost similar to that induced by the continuous 5-day treatment with $\mathrm{CN}$-A plus PEITC (Fig. 5A).

Effects of CN-A analogues on the viability of PANC-1 cells in the presence of PEITC. We next examined whether CN-A analogues and PEITC also cooperatively reduce the viability of PANC-1 cells after a short-term treatment. We previously reported that the synthetic $\mathrm{CN}-\mathrm{A}$-derivatives ISIR-005 and ISIR-042, as well as CN-A in combination with certain bioactive agents such as rapamycin and arsenic trioxide synergistically induced antitumor activities in several types of cancer cells, and that FC-J (a CN-A-related natural product) did not exert such synergistic effects $(24,25,27,28)$. As shown in Fig. 6B-D, neither ISIR-005, ISIR-042 nor FC-J reduced 

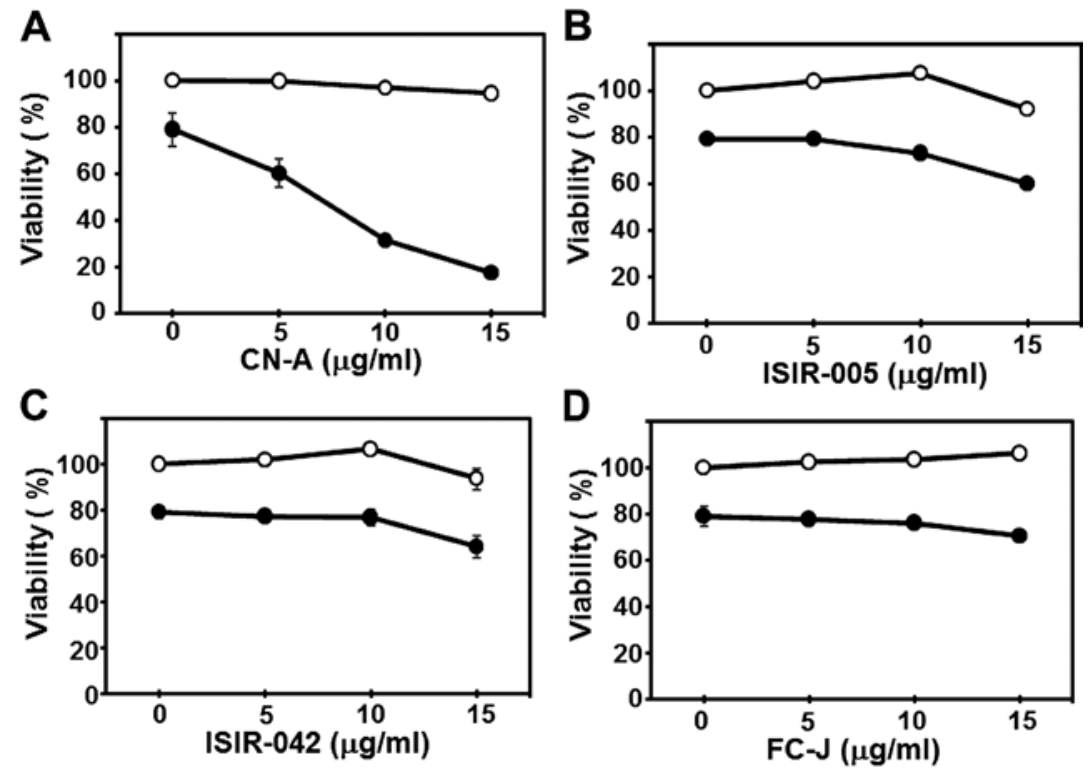

Figure 6. Effects of CN-A analogues on the viability of PANC-1 cells in the presence of PEITC. PANC-1 cells (3x10 $0^{4}$ cells $\left./ \mathrm{ml}\right)$ were cultured with CN-A (A), ISIR-005 (B), ISIR-042 (C) or FC-J (D) in the presence (closed circle) or absence (open circle) of $8 \mu \mathrm{M}$ PEITC for $16 \mathrm{~h}$. Cell viability was then determined by the MTT assay. Values are expressed as the mean \pm standard deviation of 3 determinations.

cell viability, even in the presence of $8 \mu \mathrm{M}$ PEITC for $16 \mathrm{~h}$; however, the combined treatment with CN-A and PEITC cooperatively reduced the viability of the PANC-1 cells (Fig. 6A). These results suggest that the mechanism underlying the synergistic induction of cell death induced by $\mathrm{CN}-\mathrm{A}$ plus PEITC differed from the other synergistic combination effects with CN-A, ISIR-005, or ISIR-042 plus other agents as previously reported $(24,25,27,28)$.

CN-A and PEITC synergistically trigger ROS accumulation in pancreatic cancer cells. Previous studies demonstrated that increased ROS levels are responsible for the cell death induced by PEITC $(9,12-14)$. We recently reported that the combined treatment with $\mathrm{CN}$-A plus arsenic trioxide-induced growth inhibition in breast cancer MCF-7 cells was significantly reduced by pretreatment with the antioxidant compound NAC (24). Therefore, we measured ROS levels in CN-A plus PEITC-treated pancreatic cancer cells. We evaluated the effects of the combined treatment with CN-A and PEITC on ROS generation in the MIAPaCa-2 and PANC-1 cells by flow cytometry using $10 \mu \mathrm{M} \mathrm{CM}-\mathrm{H}_{2}$ DCFDA. MIAPaCa-2 cells were treated with $20 \mu \mathrm{g} / \mathrm{ml} \mathrm{CN-A}$ and/or $4 \mu \mathrm{M}$ PEITC for $4 \mathrm{~h}$. As expected, PEITC-treated MIAPaCa-2 cells exhibited a significant increase (5-fold) in the basal ROS content. We found that the treatment with CN-A plus PEITC resulted in a marked increase ( 20 -fold) in ROS generation, whereas treatment with $\mathrm{CN}-\mathrm{A}$ alone resulted in a 2.3 -fold increase in ROS generation (Fig. 7). Similar results were obtained from PANC-1 cells treated with CN-A plus PEITC (data not shown).

ROS scavengers, NAC and trolox reverse $C N-A$ plus PEITC-induced cell death in pancreatic cancer cells. We subsequently determined whether pancreatic cancer cell death induced by the combined treatment with $\mathrm{CN}-\mathrm{A}$ and PEITC was dependent on ROS generation and mitochondrial ROS. At $16 \mathrm{~h}$, the CN-A $(15 \mu \mathrm{g} / \mathrm{ml})$ plus PEITC $(6 \mu \mathrm{M})$ treatment

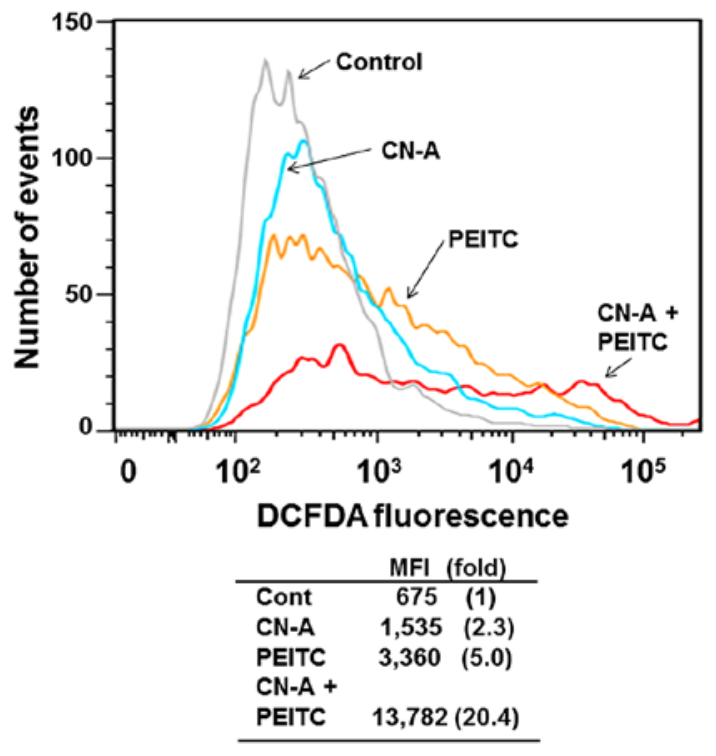

Figure 7. ROS production in MIAPaCa-2 cells treated with CN-A, PEITC or $\mathrm{CN}-\mathrm{A}$ plus PEITC. MIAPaCa-2 cells were treated with vehicle alone (grey line), $20 \mu \mathrm{g} / \mathrm{ml} \mathrm{CN-A} \mathrm{(blue} \mathrm{line),} 4 \mu \mathrm{M}$ PEITC (orange line) or $25 \mu \mathrm{g} / \mathrm{ml}$ $\mathrm{CN}-\mathrm{A}$ plus $4 \mu \mathrm{M}$ PEITC (red line) for $4 \mathrm{~h}$, and then stained with $10 \mu \mathrm{M}$ $\mathrm{CM}-\mathrm{H}_{2}$ DCFDA and subjected to flow cytometry. MFI, mean fluorescence intensity. The results shown are representative of 3 independent experiments.

markedly decreased PANC-1 cell viability to $\sim 20-30 \%$ of the control, while $\mathrm{CN}-\mathrm{A}$ alone did not significantly reduce cell viability and PEITC alone reduced viability to $\sim 80 \%$ of the control (Fig. 8). The ROS scavenger NAC (3 mM) almost completely rescued the reduction in cell viability induced by $\mathrm{CN}$-A plus PEITC (Fig. 8A). Similar results were obtained in MIAPaCa-2 cells (data not shown). Furthermore, another ROS scavenger, trolox $(0.3 \mathrm{mM})$ also canceled the reduction in cell viability induced by $\mathrm{CN}$-A plus PEITC (Fig. 8B). In contrast, the mitochondrion-specific ROS scavenger Mito-TEMPO 
A

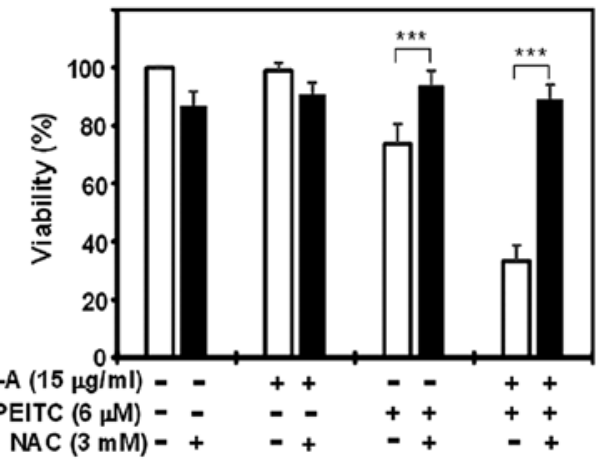

B

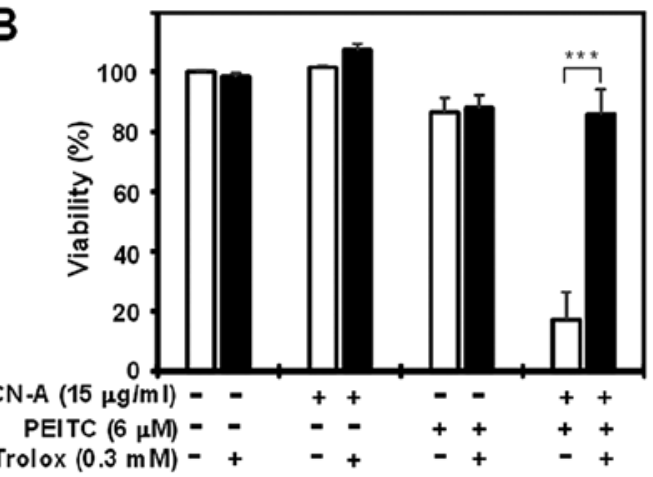

C

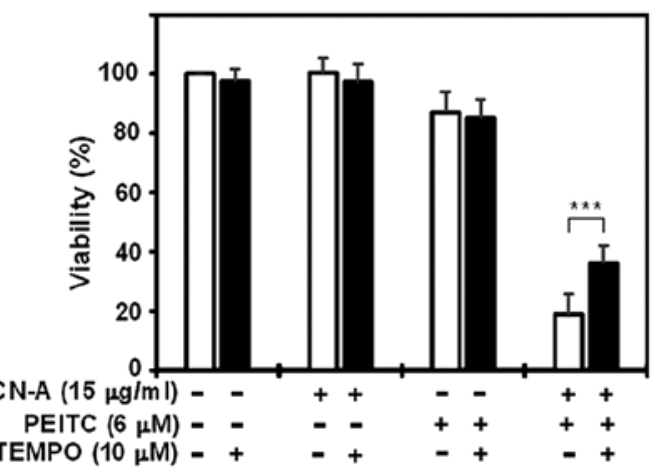

Figure 8. Effects of NAC, trolox or Mito-TEMPO on $\mathrm{CN}-\mathrm{A}$ plus PEITC-induced cell death. PANC-1 cells were treated with $15 \mu \mathrm{g} / \mathrm{ml} \mathrm{CN-A}$, $6 \mu \mathrm{M}$ PEITC or $15 \mu \mathrm{g} / \mathrm{ml} \mathrm{CN}$-A plus $6 \mu \mathrm{M}$ PEITC in the presence or absence of $3 \mathrm{mM}$ NAC (A), $0.3 \mathrm{mM}$ trolox (B) or $10 \mu \mathrm{M}$ Mito-TEMPO (C) for $16 \mathrm{~h}$. Cells were treated with NAC, trolox, or Mito-TEMPO for $2 \mathrm{~h}$ before the $\mathrm{CN}-\mathrm{A}$ and/or PEITC treatment. Cell viability was assessed by the MTT assay. Values are expressed as the mean \pm standard deviation of 3 determinations; ${ }^{* * *} \mathrm{P}<0.001$.

$(10 \mu \mathrm{M})$ only partially canceled the reduction in cell viability induced by $\mathrm{CN}-\mathrm{A}$ plus PEITC (Fig. 8C). These results suggest that ROS generation is a cause of $\mathrm{CN}$-A plus PEITC-induced cell death and that mitochondrial ROS production is not sufficient to achieve the maximal cell death activity induced by the combined treatment with CN-A and PEITC.

Combined treatment with $\mathrm{CN}-\mathrm{A}$ and PEITC activates ferroptosis in PANC-1 cells. Since it was recently reported that iron-dependent ROS production in Ras-transformed cells activates programmed necrosis in the form of ferroptosis (17), we examined the effects of the ferroptosis inhibitor Ferr-1 (17). Ferr-1 $(1.5 \mu \mathrm{M})$ almost completely prevented cell death induced by CN-A plus PEITC (Fig. 9A). In contrast, it did not prevent cell death induced by higher doses (up to $20 \mu \mathrm{M}$ ) of PEITC alone (Fig. 9B). Another potent ferroptosis inhibitor
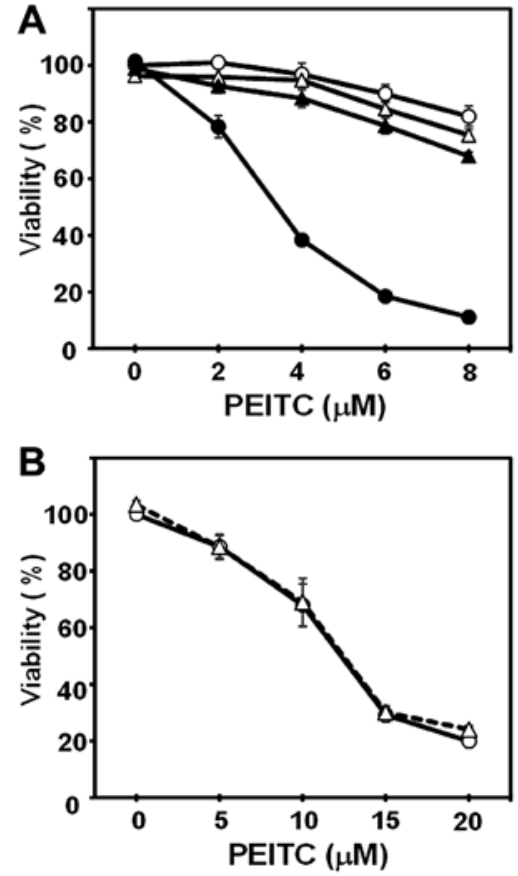

Figure 9. Effects of ferrostatin-1 (Ferr-1) on CN-A plus PEITC-induced cell death. (A) PANC-1 cells were cultured with PEITC in the absence (open circle) or presence of $15 \mu \mathrm{g} / \mathrm{ml} \mathrm{CN-A} \mathrm{(closed} \mathrm{circle)} \mathrm{for} 16 \mathrm{~h}$, or PANC-1 cells were cultured with $1.5 \mu \mathrm{M}$ Ferr-1 in the presence of PEITC (open triangle) or $15 \mu \mathrm{g} / \mathrm{ml} \mathrm{CN}$-A plus PEITC (closed triangle) for $16 \mathrm{~h}$. Ferr-1 was treated for $2 \mathrm{~h}$ before the CN-A and/or PEITC treatment. (B) PANC-1 cells were treated with PEITC at higher doses (up to $20 \mu \mathrm{M}$ ) in the presence (open circle) or absence (open triangle) of $1.5 \mu \mathrm{M}$ Ferr-1 for $16 \mathrm{~h}$. Cells were treated with Ferr- 1 for $2 \mathrm{~h}$ before the PEITC treatment. Cell viability was assessed by the MTT assay. Values are expressed as the mean \pm standard deviation of 3 determinations.

liproxstatin (Liprox, $1 \mu \mathrm{M}$ ) (29) also protected PANC-1 cells from CN-A plus PEITC-induced cell death (Fig. 10A). The co-addition of the lysosomal iron chelator deferoxamine mesylate (DFO; $0.2 \mathrm{mM}$ ) (17) fully blocked cell death induced by CN-A plus PEITC, demonstrating the iron dependency of cell death in the PANC-1 cells (Fig. 10B). Furthermore, increasing lysosomal-free iron levels by co-treatment with iron-saturated, diferric holotransferrin $(20 \mu \mathrm{g} / \mathrm{ml})$ further increased PANC-1 cell death induced by the combined treatment (data not shown). In contrast, inhibitors of other forms of cell death, including apoptosis [Z-VAD-FMK (Z-VAD), $10 \mu \mathrm{M}$ and Q-VD-OPH (QVD) (30), $20 \mu \mathrm{M}$ ] (Fig. 10C and D) and necroptosis [Nec-1s (31), $20 \mu \mathrm{M}$ ] (Fig. 11A), failed to suppress CN-A plus PEITC-induced cell death. The autophagy inhibitors (3-MA, $5 \mathrm{mM}$ and CQ, $20 \mu \mathrm{M}$ ) (32) partially prevented cell death (Fig. 11B and C). Taken together, these results suggest that synergistic cell death induced by the combined treatment with CN-A and PEITC is mainly due to the induction of ferroptosis.

\section{Discussion}

PEITC was previously shown to not only prevent the initiation phase of carcinogenesis, but also to inhibit the progression of tumorigenesis. PEITC targets multiple proteins in order to suppress various cancer-promoting mechanisms such as 
A

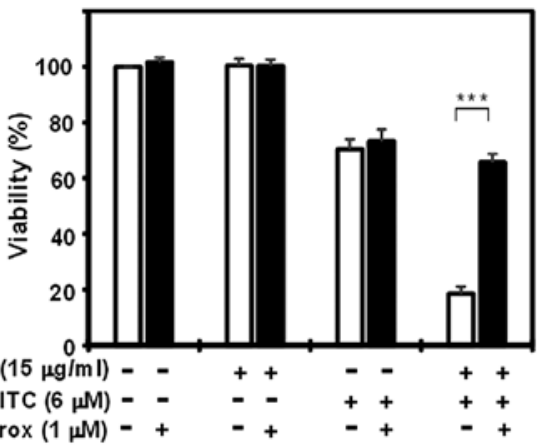

C

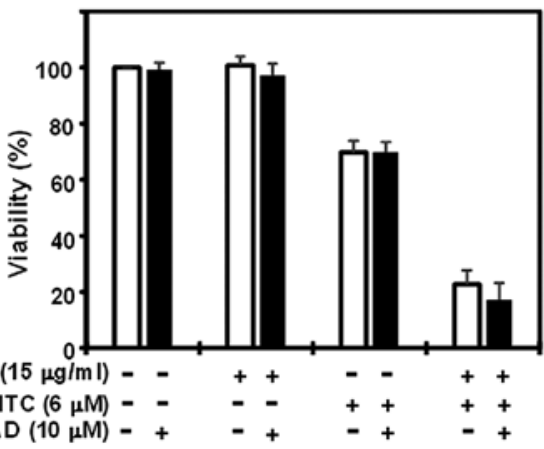

B

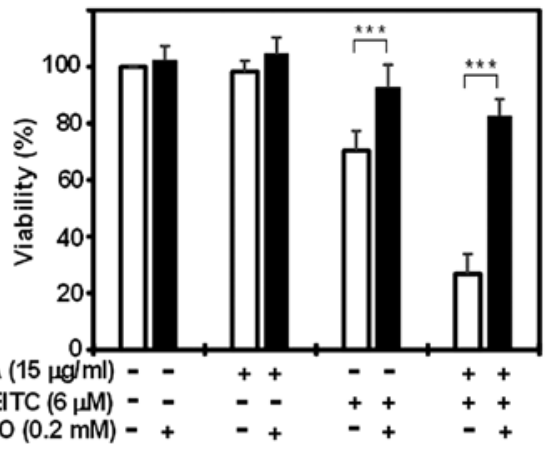

D

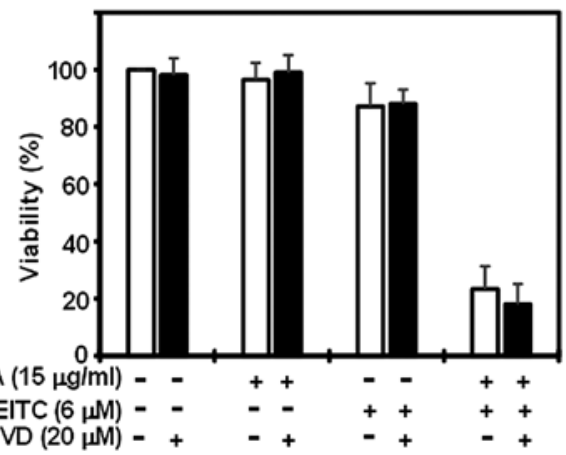

Figure 10. Effects of liproxstatin (Liprox), deferoxamine (DFO), Z-VADFMK (Z-VAD) or Q-VD-OPH (QVD) on CN-A plus PEITC-induced cell death. PANC-1 cells were treated with $15 \mu \mathrm{g} / \mathrm{ml} \mathrm{CN-A,} 6 \mu \mathrm{M}$ PEITC or $15 \mu \mathrm{g} / \mathrm{ml} \mathrm{CN-A} \mathrm{plus} 6 \mu \mathrm{M}$ PEITC in the presence or absence of $1 \mu \mathrm{M} \mathrm{Liprox} \mathrm{(A),} 0.2 \mathrm{mM}$ DFO (B), $10 \mu \mathrm{M}$ Z-VAD (C) or $20 \mu \mathrm{M}$ QVD (D) for $16 \mathrm{~h}$. Cells were treated with Liprox, DFO, Z-VAD or QVD for $2 \mathrm{~h}$ before the CN-A and/or PEITC treatment. Cell viability was assessed by the MTT assay. Values are expressed as the mean \pm standard deviation of 3 determinations; ${ }^{* * * *} \mathrm{P}<0.001$.

A

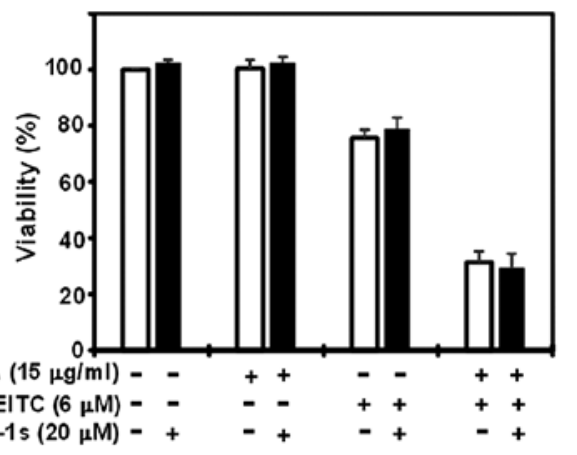

B

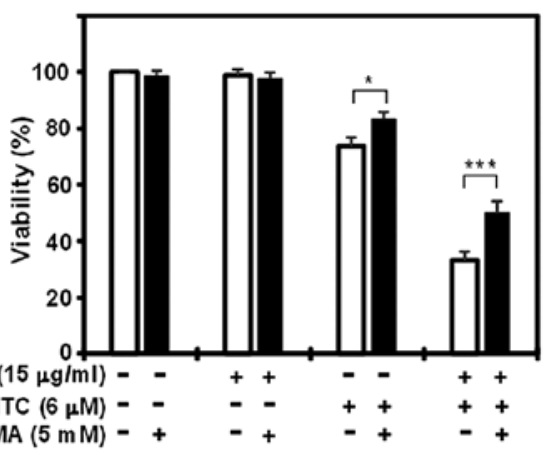

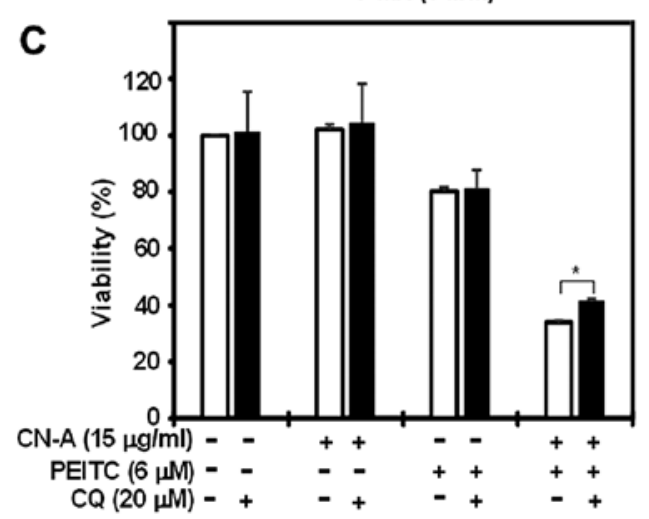

Figure 11. Effects of necrostatin-1s (Nec-1s), 3-methyladenine (3-MA) or chloroquine (CQ) on CN-A plus PEITC-induced cell death. PANC-1 cells were treated with $15 \mu \mathrm{g} / \mathrm{ml} \mathrm{CN}-\mathrm{A}, 6 \mu \mathrm{M}$ PEITC or $15 \mu \mathrm{g} / \mathrm{ml} \mathrm{CN}$-A plus $6 \mu \mathrm{M}$ PEITC in the presence or absence of $20 \mu \mathrm{M} \mathrm{Nec}-1 \mathrm{~s}$ (A), $5 \mathrm{mM} \mathrm{3-MA}$ (B) or $20 \mu \mathrm{M}$ $\mathrm{CQ}$ (C) for $16 \mathrm{~h}$. Cells were treated with Nec-1s, 3-MA or CQ for $2 \mathrm{~h}$ before the CN-A and/or PEITC treatment. Cell viability was assessed by the MTT assay. Values are expressed as the mean \pm standard deviation of 3 determinations; ${ }^{*} \mathrm{P}<0.05,{ }^{* * *} \mathrm{P}<0.001$.

cell proliferation, progression and metastasis (9). Several mechanisms have been proposed for the anticancer effects of PEITC (12,33-35). PEITC is a well-known ROS inducer in cancer cells without any potential adverse effects on normal 
cells $(14,36)$. PEITC has also been shown to activate the generation of ROS, resulting in the downstream activation of apoptotic pathways $(13,14)$. In the present study, we demonstrated that a combined treatment with CN-A and PEITC activated a form of cell death that is distinct from canonical, caspase-mediated apoptosis in pancreatic cancer cells. We initially reported that PEITC in combination with $\mathrm{CN}-\mathrm{A}$ activates an iron- and ROS-dependent form of programmed necrosis, known as ferroptosis $(17,18)$, whereas PEITC or $\mathrm{CN}$-A alone cannot induce ROS-ferroptosis pathway-mediated pancreatic cancer cell death.

We recently found that $\mathrm{CN}-\mathrm{A}$ significantly potentiated the arsenic trioxide-induced inhibition of cell growth in human breast cancer cells and that pretreatment with NAC partially rescued the growth inhibition induced by the combination of $\mathrm{CN}-\mathrm{A}$ plus arsenic trioxide. The combination of $\mathrm{CN}-\mathrm{A}$ plus arsenic trioxide also synergistically increased the expression of cleaved caspase-7 in human breast cancer MCF-7 cells and markedly inhibited the expression of survivin (24). These results suggest that oxidative responses are important events in the corporative inhibition of the growth of cancer cells induced by $\mathrm{CN}-\mathrm{A}$ and arsenic trioxide and also that the combined treatment with $\mathrm{CN}-\mathrm{A}$ and arsenic trioxide induces apoptosis in cancer cells. We speculated that the combined treatment with CN-A and ROS inducers induces effective antitumor activity against solid tumors. As described above, since PEITC is a well-known ROS inducer in cancer cells without any potential adverse effects on normal cells $(14,36)$, we determined whether the combined treatment with $\mathrm{CN}-\mathrm{A}$ and PEITC exhibits effective anticancer activity in pancreatic cancer cells. As expected, the combined treatment with CN-A and PEITC synergistically inhibited the growth of pancreatic cancer cells in a liquid culture and semisolid culture (Figs. 1 and 3). In contrast to the combined treatment with $\mathrm{CN}-\mathrm{A}$ and arsenic trioxide, CN-A plus PEITC induced robust cell death within 1 day (Figs. 4, 6 and 8) at a dose at which CN-A or PEITC alone failed to induce prominent cell death. The combined treatment with $\mathrm{CN}-\mathrm{A}$ and PEITC synergistically increased ROS levels. This robust cell death induced by CN-A plus PEITC was completely rescued by ROS scavengers (NAC and trolox) (Fig. 8A and B). However, pan-caspase inhibitors (Z-VAD and QVD) failed to rescue $\mathrm{CN}$-A plus PEITC-induced cell death (Fig. 10C and D). We considered the possibility that CN-A plus PEITC-induced cell death was not due to apoptosis. Additionally, necroptosis was excluded since necrostatin-1s did not rescue cell death induced by the combined treatment (Fig. 11A). We then explored the possibility of other forms of cell death. Our results were consistent with the recently discovered form of cell death, 'ferroptosis' $(17,18)$. Ferroptotic cell death is characterized by the loss of redox homeostasis, enhanced lipid peroxidation, and inhibition by the small molecule ferrostatin-1 (Ferr-1) or iron chelator deferoxamine. Ferroptosis inhibitors (ferrostatin-1 and liproxstatin) and deferoxamine almost completely rescued $\mathrm{CN}$-A plus PEITC-induced cell death (Figs. 9A, 10A and B). Furthermore, iron-saturated, diferric holotransferrin, which increases lysosomal-free iron levels, further enhanced cell death induced by CN-A plus PEITC (data not shown). Autophagy inhibitors (3-methyladenine and chloroquine) partially prevented combined treatment-induced cell death (Fig. 11B and C). Thus, we presently consider the combined treatment with $\mathrm{CN}-\mathrm{A}$ and PEITC-induced cell death of PANC-1 cells to be mainly due to ferroptosis rather than apoptosis and necroptosis.

We previously reported a synergistic interaction between $\mathrm{CN}-\mathrm{A}$ and rapamycin in the induction of growth arrest in mammary tumor cells $(26,27,37)$ and also observed a similar synergistic interaction between ISIR-005 (a synthetic CN-A-derivative), but not FC-J (a CN-A-related natural product), and rapamycin in the induction of growth arrest in mammary tumor cells (27). We recently found a synergistic interaction between $\mathrm{CN}-\mathrm{A}$ and arsenic trioxide in the induction of apoptosis in mammary tumor cells, and also observed a similar synergistic interaction between ISIR-005, but not FC-J, and arsenic trioxide in the induction of apoptosis in mammary tumor cells (24). ISIR-042 (another active synthetic $\mathrm{CN}$-A-derivative) plus some antitumor agents also induced synergistic effects to suppress the proliferation of solid tumor cells including pancreatic cancer cells (28). Although we expected ISIR-005 and ISIR-042 to also synergistically interact with PEITC and induce ferroptosis, similar to $\mathrm{CN}-\mathrm{A}$, ISIR-005 plus PEITC or ISIR-042 plus PEITC failed to induce synergistic cell death (Fig. 6). These results suggest that PEITC specifically interacts with $\mathrm{CN}-\mathrm{A}$, but not the other $\mathrm{CN}-\mathrm{A}$ derivatives and induces ferroptotic cell death in pancreatic cancer cells. Since only $\mathrm{CN}-\mathrm{A}$ among these $\mathrm{CN}-\mathrm{A}$ and its derivatives contains an epoxide-ring, we determined whether PEITC and an agent that contains epoxide ring(s) have the ability to induce synergistic ferroptotic cell death in PANC-1 cells. We used triptolide, a diterpene triepoxide extracted from the Chinese herb Tripterygium wilfordii with potent anticancer activity against pancreatic cancer (38), as an epoxide-containing agent. Triptolide and PEITC only additively induced cell death (data not shown). Furthermore, the additive cell death induced by triptolide plus PEITC was not rescued by the ferroptosis inhibitor ferrostain-1 (data not shown). These results suggest that agents containing epoxide do not always synergistically interact with PEITC to induce ferroptotic cell death, and that $\mathrm{CN}-\mathrm{A}$ and PEITC specifically interact and induce ferroptotic cell death. The mechanisms underlying the interaction between $\mathrm{CN}-\mathrm{A}$ and PEITC have not yet been elucidated in detail.

In conclusion, we herein demonstrated that $\mathrm{CN}-\mathrm{A}$ and PEITC cooperatively suppressed growth in pancreatic cells. Our results suggest that $\mathrm{CN}-\mathrm{A}$ and PEITC induced ferroptotic cell death in pancreatic cancer PANC-1 cells, whereas CN-A or PEITC alone did not. These results suggest that the combination of CN-A and PEITC may become a novel therapeutic strategy against pancreatic cancer.

\section{Acknowledgements}

The present study was partly supported by grants (nos. 25462007 and 16K10459) from the Ministry of Education, Culture, Sports, Science and Technology of Japan and by a grant from the Shimane University 'SUIGAN' project.

\section{References}

1. Siegel R, Ma J, Zou Z and Jemal A: Cancer statistics, 2014. CA Cancer J Clin 64: 9-29, 2014. 
2. Hidalgo M: Pancreatic cancer. N Engl J Med 362: 1605-1617, 2010.

3. Burris HA III, Moore MJ, Andersen J, Green MR, Rothenberg ML, Modiano MR, Cripps MC, Portenoy RK, Storniolo AM, Tarassoff $\mathrm{P}$, et al: Improvements in survival and clinical benefit with gemcitabine as first-line therapy for patients with advanced pancreas cancer: A randomized trial. J Clin Oncol 15: 2403-2413, 1997.

4. Kroep JR, Pinedo HM, van Groeningen CJ and Peters GJ: Experimental drugs and drug combinations in pancreatic cancer. Ann Oncol 10 (Suppl 4): S234-S238, 1999.

5. Jakstaite A, Maziukiene A, Silkuniene G, Kmieliute K, Gulbinas A and Dambrauskas Z: HuR mediated post-transcriptional regulation as a new potential adjuvant therapeutic target in chemotherapy for pancreatic cancer. World J Gastroenterol 21: 13004-13019, 2015.

6. Guilford JM and Pezzuto JM: Natural products as inhibitors of carcinogenesis. Expert Opin Investig Drugs 17: 1341-1352, 2008.

7. Higdon JV, Delage B, Williams DE and Dashwood RH: Cruciferous vegetables and human cancer risk: Epidemiologic evidence and mechanistic basis. Pharmacol Res 55: 224-236, 2007.

8. Tang L, Zirpoli GR, Guru K, Moysich KB, Zhang Y, Ambrosone $\mathrm{CB}$ and McCann SE: Intake of cruciferous vegetables modifies bladder cancer survival. Cancer Epidemiol Biomarkers Prev 19: 1806-1811, 2010

9. Gupta P, Wright SE, Kim SH and Srivastava SK: Phenethyl isothiocyanate: A comprehensive review of anti-cancer mechanisms. Biochim Biophys Acta 1846: 405-424, 2014.

10. Satyan KS, Swamy N, Dizon DS, Singh R, Granai CO and Brard L: Phenethyl isothiocyanate (PEITC) inhibits growth of ovarian cancer cells by inducing apoptosis: Role of caspase and MAPK activation. Gynecol Oncol 103: 261-270, 2006.

11. Wu X, Zhou QH and Xu K: Are isothiocyanates potential anticancer drugs? Acta Pharmacol Sin 30: 501-512, 2009.

12. Hong YH, Uddin MH, Jo U, Kim B, Song J, Suh DH, Kim HS and Song YS: ROS accumulation by PEITC selectively kills ovarian cancer cells via UPR-mediated apoptosis. Front Oncol 5 : $167,2015$.

13. Trachootham D, Zhou Y, Zhang H, Demizu Y, Chen Z, Pelicano H, Chiao PJ, Achanta G, Arlinghaus RB, Liu J, et al Selective killing of oncogenically transformed cells through a ROS-mediated mechanism by beta-phenylethyl isothiocyanate. Cancer Cell 10: 241-252, 2006.

14. Xiao D, Powolny AA, Moura MB, Kelley EE, Bommareddy A, Kim SH, Hahm ER, Normolle D, Van Houten B and Singh SV: Phenethyl isothiocyanate inhibits oxidative phosphorylation to trigger reactive oxygen species-mediated death of human prostate cancer cells. J Biol Chem 285: 26558-26569, 2010.

15. Shaw AT, Winslow MM, Magendantz M, Ouyang C, Dowdle J, Subramanian A, Lewis TA, Maglathin RL, Tolliday N and Jacks T: Selective killing of K-ras mutant cancer cells by small molecule inducers of oxidative stress. Proc Natl Acad Sci USA 108: 8773-8778, 2011.

16. Yang WS and Stockwell BR: Synthetic lethal screening identifies compounds activating iron-dependent, nonapoptotic cell death in oncogenic-RAS-harboring cancer cells. Chem Biol 15: 234-245, 2008.

17. Dixon SJ, Lemberg KM, Lamprecht MR, Skouta R, Zaitsev EM, Gleason CE, Patel DN, Bauer AJ, Cantley AM, Yang WS, et al: Ferroptosis: An iron-dependent form of nonapoptotic cell death Cell 149: 1060-1072, 2012

18. Yang WS and Stockwell BR: Ferroptosis: Death by lipid peroxidation. Trends Cell Biol 26: 165-176, 2016.

19. Sassa T, Tojyo T and Munakata K: Isolation of a new plant growth substance with cytokinin-like activity. Nature 227: 379, 1970

20. Asahi K, Honma Y, Hazeki K, Sassa T, Kubohara Y, Sakurai A and Takahashi N: Cotylenin A, a plant-growth regulator, induces the differentiation in murine and human myeloid leukemia cells. Biochem Biophys Res Commun 238: 758-763, 1997.

21. Yamamoto-Yamaguchi Y, Yamada K, Ishii Y, Asahi KI, Tomoyasu S and Honma Y: Induction of the monocytic differentiation of myeloid leukaemia cells by cotylenin A, a plant growth regulator. Br J Haematol 112: 697-705, 2001.

22. Yamada K, Honma Y, Asahi KI, Sassa T, Hino KI and Tomoyasu S: Differentiation of human acute myeloid leukaemia cells in primary culture in response to cotylenin A, a plant growth regulator. Br J Haematol 114: 814-821, 2001.
23. Honma Y: Cotylenin A - a plant growth regulator as a differentiation-inducing agent against myeloid leukemia. Leuk Lymphoma 43: 1169-1178, 2002.

24. Kasukabe T, Okabe-Kado J, Kato N, Honma Y and Kumakura S: Cotylenin A and arsenic trioxide cooperatively suppress cell proliferation and cell invasion activity in human breast cancer cells. Int J Oncol 46: 841-848, 2015.

25. Kawakami K, Hattori M, Inoue T, Maruyama Y, Ohkanda J, Kato N, Tongu M, Yamada T, Akimoto M, Takenaga K, et al: A novel fusicoccin derivative preferentially targets hypoxic tumor cells and inhibits tumor growth in xenografts. Anticancer Agents Med Chem 12: 791-800, 2012.

26. Kasukabe T, Okabe-Kado J, Kato N, Sassa T and Honma Y: Effects of combined treatment with rapamycin and cotylenin A, a novel differentiation-inducing agent, on human breast carcinoma MCF-7 cells and xenografts. Breast Cancer Res 7: R1097-R1110, 2005.

27. Kasukabe T, Okabe-Kado J, Haranosono Y, Kato N and Honma Y: Inhibition of rapamycin-induced Akt phosphorylation by cotylenin A correlates with their synergistic growth inhibition of cancer cells. Int J Oncol 42: 767-775, 2013.

28. Miyake T, Honma Y,Urano T, Kato N and Suzumiya J: Combined treatment with tamoxifen and a fusicoccin derivative (ISIR-042) to overcome resistance to therapy and to enhance the antitumor activity of 5-fluorouracil and gemcitabine in pancreatic cancer cells. Int J Oncol 47: 315-324, 2015.

29. Friedmann Angeli JP, Schneider M, Proneth B, Tyurina YY, Tyurin VA, Hammond VJ, Herbach N, Aichler M, Walch A, Eggenhofer E, et al: Inactivation of the ferroptosis regulator $\mathrm{Gpx} 4$ triggers acute renal failure in mice. Nat Cell Biol 16: 1180-1191, 2014.

30. Xargay-Torrent S, López-Guerra M, Montraveta A, SaboritVillarroya I, Rosich L, Navarro A, Pérez-Galán P, Roué G, Campo E and Colomer D: Sorafenib inhibits cell migration and stroma-mediated bortezomib resistance by interfering B-cell receptor signaling and protein translation in mantle cell lymphoma. Clin Cancer Res 19: 586-597, 2013.

31. Takahashi N, Duprez L, Grootjans S, Cauwels A, Nerinckx W, DuHadaway JB, Goossens V, Roelandt R, Van Hauwermeiren F, Libert C, et al: Necrostatin-1 analogues: Critical issues on the specificity, activity and in vivo use in experimental disease models. Cell Death Dis 3: e437, 2012.

32. Carew JS, Nawrocki ST, Giles FJ and Cleveland JL: Targeting autophagy: A novel anticancer strategy with therapeutic implications for imatinib resistance. Biologics 2: 201-204, 2008.

33. Keum YS, Jeong WS and Kong AN: Chemoprevention by isothiocyanates and their underlying molecular signaling mechanisms. Mutat Res 555: 191-202, 2004.

34. Chen YR, Wang W, Kong AN and Tan TH: Molecular mechanisms of c-Jun N-terminal kinase-mediated apoptosis induced by anticarcinogenic isothiocyanates. J Biol Chem 273: 1769-1775, 1998.

35. Yang YM, Conaway CC, Chiao JW, Wang CX, Amin S, Whysner J, Dai W, Reinhardt J and Chung FL: Inhibition of benzo(a)pyrene-induced lung tumorigenesis in $\mathrm{A} / \mathrm{J}$ mice by dietary $N$-acetylcysteine conjugates of benzyl and phenethyl isothiocyanates during the postinitiation phase is associated with activation of mitogen-activated protein kinases and p53 activity and induction of apoptosis. Cancer Res 62: 2-7, 2002.

36. Jutooru I, Guthrie AS, Chadalapaka G, Pathi S, Kim K, Burghardt R, Jin UH and Safe S: Mechanism of action of phenethylisothiocyanate and other reactive oxygen species-inducing anticancer agents. Mol Cell Biol 34: 2382-2395, 2014.

37. Kasukabe T, Okabe-Kado J and Honma Y: Cotylenin A, a new differentiation inducer, and rapamycin cooperatively inhibit growth of cancer cells through induction of cyclin G2. Cancer Sci 99: 1693-1698, 2008.

38. Mujumdar N, Mackenzie TN, Dudeja V, Chugh R, Antonoff MB Borja-Cacho D, Sangwan V, Dawra R, Vickers SM and Saluja AK: Triptolide induces cell death in pancreatic cancer cells by apoptotic and autophagic pathways. Gastroenterology 139: 598-608, 2010 